\title{
Investigation of indoor microclimate of historic libraries for preventive conservation of manuscripts. Case Study: Tire Necip Paşa Library, İzmir-Turkey
}

\author{
Cem Doğan Sahin ${ }^{\mathrm{a}}$, Turgay Coşkun ${ }^{\mathrm{b}}$, Zeynep Durmuş Arsan ${ }^{\mathrm{c}, *}$, Gülden Gökçen Akkurt ${ }^{\mathrm{d}}$ \\ a Department of Mechanical Engineering, Izmir Institute of Technology, Izmir, Turkey \\ ${ }^{\mathrm{b}}$ Energy Engineering Programme, Izmir Institute of Technology, Izmir, Turkey

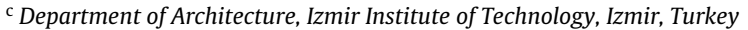 \\ ${ }^{\mathrm{d}}$ Department of Energy Systems Engineering, Izmir Institute of Technology, Izmir, Turkey
}

\section{A R T I C L E I N F O}

\section{Article history:}

Received 29 August 2016

Received in revised form 7 November 2016

Accepted 8 November 2016

Available online 24 November 2016

\section{Keywords:}

Manuscripts

Degradation

Risk assessment

Preventive conservation

Historic library

Indoor climate

\begin{abstract}
A B S T R A C T
Conservation of library collections requires an interdisciplinary approach. Dealing with the agents of deterioration via curative and preventive conservation methods has become a significant goal with new standards and norms in recent years. Preventive conservation aims indirect physical interventions such as climate control, good housekeeping and pest management. The aim of this study is to assess the degradation potential of indoor climate on valuable manuscripts that date back to 12 th century, in a historic library in Tire-İzmir, Turkey. Through the study, first the library, namely Necip Paşa Library was continuously monitored by measurements of thermo-hygrometric parameters for one year. Then, the measured data were evaluated for the risk assessment based on the control classes of ASHRAE Chapter 21 to evaluate the mechanical, chemical and biological degradation risks. Finally, the conservation-oriented measures were proposed in order to keep the manuscripts under the better conditions.

Results suggest that introducing a heating, ventilation and air-conditioning system to the building should be considered as the last option since natural hygrothermal behavior of the library gives reasonably sufficient evidences to prevent the manuscripts from degradations to some extent. Therefore, passive solutions should be given higher priorities not to disturb environmental past of the historic library.
\end{abstract}

(c) 2016 Elsevier Ltd. All rights reserved.

\section{Introduction}

Indoor climate is of great significance not only for the comfort of human beings but also for the conservation of tangible values, cultural properties and human heritage. It is widely known that the collections having cultural heritage values can deteriorate in the places they have been stored or exhibited (Karaca, Alagha, \& Gören, 2009). This phenomenon occurs mainly due to the inadequate indoor environmental conditions depending on the quantitative parameters such as temperature $(\mathrm{T})$, relative humidity $(\mathrm{RH})$, illuminance level, indoor air pollutants, etc. (Fabbri \& Pretelli, 2014; Karaca et al., 2009; La Gennusa, Rizzo, Scaccianoce, \& Nicoletti, 2005). Therefore, it has become a significant goal to deal and tackle with the agents of deterioration via curative (remedial, active) and preventive (passive) conservation methods. Curative conservation

\footnotetext{
* Corresponding author at: Department of Architecture, Izmir Institute of Technology, Gülbahçe, Urla-İzmir TR-35430, Turkey.

E-mail address: zeynepdurmus@iyte.edu.tr (Z.D. Arsan).
}

concerns direct actions such as stabilization, consolidation and disinfestation on the cultural property while preventive conservation aims indirect physical interventions on collections that are, in general, (Bülow, 2002; de Guichen, 1999):

- Assessment of conservation status and needs of collection,

- Environmental monitoring and control of storage and exhibition areas,

- Design and implementation of a disaster plan,

- Good housekeeping,

- Integrated pest management,

- Proper housing and mounting of objects,

- Appropriate storage facilities,

- Education and training of staff.

However, it might be challenging to entirely provide the abovementioned interventions due to some constraints whilst recommended indoor environmental conditions can be obtained 


\begin{tabular}{|c|c|}
\hline \multicolumn{2}{|c|}{ Nomenclature } \\
\hline$a$ & Point in seasonal period \\
\hline ACH50 & Air exchange rate at $50 \mathrm{~Pa}$ pressure difference \\
\hline $\mathrm{AH}$ & Absolute humidity $\left[\mathrm{kg}_{\mathrm{air}} / \mathrm{m}^{3}{ }_{\text {air }}\right]$ \\
\hline$E_{a}$ & $\begin{array}{l}\text { Activation energy [ } 100 \mathrm{~kJ} / \mathrm{mol} \text { for degradation of cel- } \\
\text { lulose] }\end{array}$ \\
\hline$e L M$ & Equivalent lifetime multiplier \\
\hline HVAC & Heating, ventilation and air-conditioning \\
\hline$i$ & Data point in the data range \\
\hline LM & Lifetime multiplier \\
\hline MRF & Mould risk factor \\
\hline$n$ & Number of data points \\
\hline$N$ & Correction factor \\
\hline $\mathrm{R}$ & Gas constant $[8.314 \mathrm{~J} / \mathrm{molK}]$ \\
\hline RH & Relative humidity [\%] \\
\hline$R H_{\text {crit }}$ & Critical relative humidity for porous materials [\%] \\
\hline$R H_{c r i t, w}$ & Critical relative humidity for wooden materials [\%] \\
\hline SRA & Seasonal running average \\
\hline $\mathrm{T}$ & Temperature $\left[{ }^{\circ} \mathrm{C}\right]$ \\
\hline $\mathrm{x}$ & Data point in data series \\
\hline $\bar{X}$ & Annual mean in $\mathrm{t}\left[{ }^{\circ} \mathrm{C}\right]$ or $\mathrm{RH}[\%]$ \\
\hline$X$ & $\mathrm{~T}\left[{ }^{\circ} \mathrm{C}\right]$ or $\mathrm{RH}[\%]$ \\
\hline$X_{\text {running }}$ & Seasonal running average in $\mathrm{t}\left[{ }^{\circ} \mathrm{C}\right]$ or $\mathrm{RH}[\%]$ \\
\hline$X_{\text {rise }}$ & Seasonal rise in $\mathrm{t}\left[{ }^{\circ} \mathrm{C}\right]$ or $\mathrm{RH}[\%]$ \\
\hline$X_{\text {drop }}$ & Seasonal drop in $\mathrm{t}\left[{ }^{\circ} \mathrm{C}\right]$ or $\mathrm{RH}[\%]$ \\
\hline
\end{tabular}

controlling the prioritized quantitative parameters via passive only solutions-usually applied in the past-and/or mechanical systems.

Nowadays, indoor climate in modern buildings can be simply conditioned with the help of heating, ventilation and airconditioning (HVAC) systems while it was not possible to do so for historic buildings. On the other hand, some historic buildings have unique architectural features and hygrothermal behavior and were deliberately designed considering primarily the purpose of use and climate of the place they had been built (Padfield, Larsen, Jensen, \& Ryhl-Svendsen, 2007). For example, historic museums, libraries, baths, sanctuaries were intentionally constructed with passive architectural control mechanisms/solutions in order to meet heating, cooling and ventilation issues and to maintain adequate indoor environment for variable purposes (Bülow, 2002). Along with the developing technology, higher comfort inquiries and conservation concerns, an awareness has been raised for changing and re-defining the indoor comfort conditions. As an outcome of these issues; new methods, regulations and standards were introduced for new buildings (ANSI/ASHRAE Standard 552013, 2013; CEN European Committee for Standardisation, 2007; Costanzo, Cusumano, Giaconia, \& Giaconia, 2006). At the same time, it was realized that the microclimatic conditions in historic buildings without HVAC system were relatively inadequate and should be improved. Thus, historic buildings were offered a number of measures such as internal/external insulation, replacing windows with the ones having better thermal properties, an advanced HVAC system and its control in order to comply with the standards and regulations (Fabbri \& Pretelli, 2014; Şahin, Durmuş Arsan, Tunçoku, Broström, \& Gökçen Akkurt, 2015). At this point, measures need to be assessed with a holistic point of view since historic buildings require special treatment in terms of sustainability of their tangible and intangible heritage values (Broström et al., 2014; Bülow, 2002; Şahin et al., 2015).

Indoor environmental control of historic buildings that have no HVAC system is essential since degradation phenomena are highly interrelated with the past environmental history of the buildings which is mostly driven by moisture buffering capacity of paperbased collections, as well as the airtightness and massive thermal mass of the building fabric (Bülow, 2002; D'agostino, Alfano, Palella, \& Riccio, 2015). At this point, it is paramount to state that historic buildings being deliberately designed as library and have no HVAC system should be well-investigated and thermo-hygrometric parameters need to be controlled with higher priority since disturbing past environmental history of the building might eventually become an agent of deterioration. In order such degradations to be prevented, paper-based collections need to be stored in more stable indoor climate with recommended fluctuations (Bülow, 2002; Steeman, De Paepe, \& Janssens, 2010). For this reason, a number of methods, guidelines and standards have been introduced to control and evaluate the indoor climate of buildings which contains precious cultural properties such as books, manuscripts, paintings, and sculptures (ASHRAE, 2007; Bülow, 2002; Corgnati \& Filippi, 2010; EN, 2010a; Krüger \& Diniz, 2010; UNI, 1999; PAS, 2012; Silva \& Henriques, 2014; Silva \& Henriques, 2015).

The common approach for libraries is to preserve the paperbased collections from the irreversible deterioration with the control of the quantitative parameters. When indoor environmental control is of primary interest in libraries, it is to give higher priority to the thermo-hygrometric parameters, which requires more straightforward interventions rather than controlling $\mathrm{NO}_{\mathrm{x}}$, $\mathrm{SO}_{2}, \mathrm{O}_{3}$, particulate matter (Andretta, Coppola, \& Seccia, 2015). Thus, providing such indoor climate by controlling the fluctuations of $\mathrm{T}$ and $\mathrm{RH}$ and some synthetic parameters based on $\mathrm{T}$ and $\mathrm{RH}$ (i.e. LM, eLM, MRF) in recommended levels will increase the life-time of the paper-based collections (Bülow, 2002; Corgnati \& Filippi, 2010). Besides, other quantitative parameters associated with indoor environmental quality such as $\mathrm{NO}_{\mathrm{x}}, \mathrm{SO}_{2}, \mathrm{O}_{3}$ and particulate matter and the light exposure are taken into consideration according to the material properties of the cultural property (Andretta et al., 2015; Brimblecombe et al., 1999; Bülow, 2002; D’agostino et al., 2015; Fabbri \& Pretelli, 2014; Krüger \& Diniz, 2010; La Gennusa et al., 2005). Many studies that investigate preventive conservation of paper-based collections mainly comprise of the mechanical, chemical and biological degradation. Therefore, each degradation phenomenon has been investigated with the monitoring and evaluation of thermo-hygrometric parameters (Bülow, 2002; D’agostino et al., 2015; Krüger \& Diniz, 2010; Silva \& Henriques, 2015; Martens, 2012).

It is necessary to indicate that there has been no methodology, directive or regulation to cover the preventive conservation of paper-based collections, in Turkey. In addition, the number of similar studies regarding this field is relatively insufficient and the assessments in the today's national literature generally were centralized around dealing with the curative conservation rather than preventive (Baydar, 2001; Kuzucuoğlu, 2014; Kuzucuoğlu, Kiraz, Ünsalan, \& Taşdemir, 2015; Şahiner, 2006). In the case that the restoration projects are carried out without a holistic and transdisciplinary approach, unexpected and harmful consequences may possibly occur accordingly. Therefore, having a national methodology, directive or regulation is a need to regulate corresponding issues.

The primary aim of this study is to investigate the indoor microclimate of a historic library through monitoring thermohygrometric parameters and to determine whether is favorable for the preventive conservation of the manuscripts in Necip Pașa Library, Tire-İzmir, Turkey. The library has no heating/cooling and mechanical ventilation system. A restoration work, which includes an HVAC system installation, is about to proceed. This issue, therefore, raises a need to analyze the actual hygrothermal performance of the library before the restoration work.

It is essential to indicate that the HVAC installation was proposed to the library without an in-depth analysis of the 
hygrothermal behavior of the building and its effects on the manuscripts. At this point, one must remember that historic buildings have the potential to perform in favor of conservation of paper-based collections because their substantial fabric might provide a relatively more stable indoor climate (Bülow, 2002). Besides, studies conducted in historic libraries in Mediterranean Climate point out that free-floating hygrothermal behavior of historic buildings reasonably satisfy the preventive conservation requirements thanks to the high thermal inertia and low airtightness value of the buildings (Fabbri \& Pretelli, 2014; Andretta et al., 2015). Therefore, controlling the indoor microclimate with mechanical systems might not be the first choice. If necessary, HVAC systems should be designed primarily taking into account of the preventive conservation requirements rather than human comfort (Fabbri \& Pretelli, 2014).

Therefore, the study concerns whether the passive, (freefloating) hygrothermal behavior of the historic library is sufficient to preserve the manuscripts through the requirements in accordance with ASHRAE Chapter 21, or an HVAC system is required (ASHRAE, 2007). With the present study, it was also aimed to make contribution to the current literature in Turkey regarding the significance of preventive conservation of manuscripts from quantitative point of view and to increase awareness of academic and administrative authorities upon this issue.

\subsection{Types of degradation}

In this study, the effect of thermo-hygrometric parameters upon mechanical, chemical and biological degradation of manuscripts will be investigated. In order to better understand the degradation phenomena, the relationship between moisture and paper should be clarified since it changes several significant properties such as weight, diffusivity, strength, dimensional stability and permanence. Paper tends to adsorb and desorb moisture in unstable indoor climates while seeks to reach equilibrium with the environment under steady conditions. The moisture transfer from/to paper starts at time that the indoor $\mathrm{RH}$ is lower/higher than that of the material. This is subjected to the buffer capacity of paper. Buffering is referred to the ability of paper to react to and moderate fluctuations in indoor RH. Additionally, it must be kept in mind that cyclic humidity changes cause variations in moisture content, which have damaging impacts on paper. Besides, high moisture content over a long period of time will expectedly decrease the overall lifetime of paper and act as a good environment in favor of mould germination (Bülow, 2002). In the following sub-sections, mechanisms of three degradation phenomena, i.e. mechanical, chemical and biological, will be explained taking into account of the relationship between paper and moisture.

\subsubsection{Mechanical degradation}

Mechanical degradation is generally subjected to externally applied forces and short time fluctuations of RH such as on hourly, daily and weekly basis (Bülow, 2002; Martens, 2012). The moisture content of the organic hygroscopic materials is driven by the fluctuations of indoor $\mathrm{T}$ and $\mathrm{RH}$, which can, in turn, cause significant degradation phenomena such as tearing, swelling, embrittlement and dimensional changes (Silva \& Henriques, 2015).

Since paper, in general, absorbs moisture faster than it desorbs, the most stressful fluctuations are those that are longer than the response time, but shorter than the stress relaxation time. Due to the fact that the extent of damage is subjected significantly to the geometry of the assembly, even stresses lower than critical value might cause damage. Most paper objects are durable and can survive a daily drop of $25 \% \mathrm{RH}$. Yet at the same time, ink on parchment can become brittle hence highly vulnerable at low humidity (Michalski, 1993).
Particularly, high moisture content together with stress can cause relaxation, trigger the mechanical degradation and lead to irreversible deformation in physical structure (Bülow, 2002). It is a particular concern that maps or the manuscripts including a scaled map require dimensional stability of paper since the accuracy of scale is jeopardized due to the varying degree of response of the different materials to changes in relative humidity (Bülow, 2002). Therefore, more stable microclimatic conditions in libraries are essential for the preventive conservation of paper-based collections; otherwise those may structurally suffer.

\subsubsection{Chemical degradation}

Chemical degradation, which is highly dependent on the amount of moisture content in hygroscopic materials, may cause discoloration in papers and deterioration in text. The lower the moisture content, the slower the deterioration. Depending on the papermaking process and the paper structure, the moisture transport properties of paper may differ (Derluyn, Janssen, Diepens, Derome, \& Carmeliet, 2007). In addition, that chemical processes slow down at low temperatures. Therefore, long-term collections and archives are required to be stored under low T and RH (Martens, 2012; PAS, 2012). In the literature, it was claimed that $5 \mathrm{~K}$ decrement in temperature that is around $20^{\circ} \mathrm{C}$ duplicates the lifetime for the most objects (Michalski, 2003). Therefore, a parameter especially significant for paper objects, named as Lifetime Multiplier (LM), was introduced, which corresponds to the number of time spans an object remains usable when compared to indoor climate of $20^{\circ} \mathrm{C}$ and 50\% RH (Martens, 2012; Silva \& Henriques, 2015).

\subsubsection{Biological degradation}

Microorganisms usually move into the indoor environment through the air transfer mechanisms such as infiltration, natural and mechanical ventilation or human activity and later seek for optimal conditions to germinate. Due to the organic nature and its hygroscopic properties, paper can be referred as a good source of nourishment for mould and other microorganisms (Bülow, 2002). Besides, mould can germinate using almost every natural substance as a source of carbon and energy providing that the water is sustained (Bülow, 2002). Biological degradation, which hereby corresponds to mould growth on the surface of manuscripts, is associated with T, RH and substrate. The existence of these parameters in optimal critical conditions over a certain time stimulates the mould growth (Huijbregts, Kramer, Martens, van Schijndel, \& Schellen, 2010). In the literature, a number of mould risk prediction models taking into account the critical boundary conditions based on thermo-hygrometric parameters have been improved and each of these models were compared in terms of their capabilities (Rowan, Johnstone, McLean, Anderson, \& Clarke, 1999; Vereecken \& Roels, 2010). The prediction models, namely IEA-Annex 14, timeof-wetness, Johansson's mould growth indices, fungal index, VIT model, updated VIT model, isopleth models, Ayerst and Smith and Hill, ESP-r model, Hens, Sedlbauer, mould germination graph method, give realistic results regarding the risk assessment of mould growth (Vereecken \& Roels, 2010).

\subsection{Airtightness}

Airtightness is the fundamental parameter that drives infiltration along the building space. Although it can be defined in variety of ways, infiltration is simply the air movement through cracks, leaks and other (un)intended openings on the building envelope (Sherman \& Chan, 2004). The more airtight the building, the less air in the building will change over time, or vice versa. Therefore, it is essential to control airtightness in the buildings, which have no 
Table 1

Summary of indoor climate conditions of ASHRAE Chapter 21 (ASHRAE, 2007).

\begin{tabular}{|c|c|c|c|c|c|}
\hline Type & Set-point or Annual average & $\begin{array}{l}\text { Class of } \\
\text { control }\end{array}$ & & Short fluctuations & Seasonal adjustments in system set point \\
\hline $\begin{array}{l}\text { General Museums, Art } \\
\text { Galleries, Libraries and } \\
\text { Archives }\end{array}$ & $\begin{array}{l}50 \% \mathrm{RH} \text { (or historic annual average for } \\
\text { permanent collections) T set between } 15 \\
\text { and } 25^{\circ} \mathrm{C} \\
\text { Note: rooms intended for loan exhibitions } \\
\text { must handle set point specified in load } \\
\text { agreement, typically } 50 \% \mathrm{RH}, 21^{\circ} \mathrm{C} \text { but } \\
\text { sometimes } 55 \text { or } 60 \% \mathrm{RH}\end{array}$ & $\begin{array}{l}\text { AA } \\
\text { A }\end{array}$ & $\begin{array}{l}\mathrm{A}_{1} \\
\mathrm{~A}_{2}\end{array}$ & $\begin{array}{l} \pm 5 \% \mathrm{RH}, \pm 2 \mathrm{~K} \\
\pm 5 \% \mathrm{RH}, \pm 2 \mathrm{~K} \\
\pm 10 \% \mathrm{RH}, \pm 2 \mathrm{~K} \\
\pm 10 \% \mathrm{RH}, \pm 5 \mathrm{~K} \\
\\
\text { Within } 25-75 \% \mathrm{RH} \\
\text { T rarely over } 30{ }^{\circ} \mathrm{C}, \\
\text { Reliably below } 75 \%\end{array}$ & $\begin{array}{l}\text { RH no change; Up } 5 \mathrm{~K} \text {, down } 5 \mathrm{~K} \\
\text { Up } 10 \% \mathrm{RH} \text {, down } 10 \% \mathrm{RH} \text {; Up } 5 \mathrm{~K} \text {, down } 10 \mathrm{~K} \\
\text { No RH change; Up } 5 \mathrm{~K} \text {, down } 10 \mathrm{~K} \\
\text { Up } 10 \% \mathrm{RH} \text {, down } 10 \% \mathrm{RH} \text {; Up } 10 \mathrm{~K} \text { but not above } \\
30^{\circ} \mathrm{C} \text {, down as low as necessary to maintain } \mathrm{RH} \\
\text { control } \\
\text { ear-round } \\
\text { sually below } 25^{\circ} \mathrm{C} \\
\text { R }\end{array}$ \\
\hline
\end{tabular}

HVAC systems, in order to control the short T and RH fluctuations within the allowable limits (Luciani, Wessberg, \& Broström, 2013).

\subsection{Indoor microclimate requirements}

The ASHRAE Chapter 21 (ASHRAE, 2007) introduces control classes to assess the mechanical, chemical and biological degradation potential of paper-based collections in libraries, museums, art galleries and archives. Summary of the classes is given in Table 1.

The guideline simply indicates that the objects should be stored either due to set points ( $\mathrm{T}$ between 15 and $25^{\circ} \mathrm{C}, \mathrm{RH} 50 \%$ ) or historic annual average value when permanent collections are of interests. Moreover, indoor climate is expected to be kept within a range which may differ due to the recommended seasonal and short fluctuations provided that they are not exceeded. If the indoor climate satisfies the requirements indicated in any class of control, the objects can be assumed as preserved against major and minor risks of degradation. If not, some major and/or minor damages can be observed depending on the unsatisfied requirement such as excessive daily $\mathrm{T}$ change or seasonal $\mathrm{RH}$ rise/drop.

Class AA is the most optimal one that no risk of mechanical damage is expected for most objects. According to this class, T fluctuations shorter than seasonal, such as weekly, daily, hourly are allowed up to $\pm 2 \mathrm{~K}$ while that of $\mathrm{RH}$ is only $\pm 5 \%$. In addition, no seasonal fluctuation of $\mathrm{RH}$ is permitted while $\mathrm{T}$ fluctuations are expected to be in the range of $\pm 5 \mathrm{~K}$.

In Class A, there are two sub-classes (herein referred to A1 and A2) which are distinguished due to small differences. In the subclass of A1, short T fluctuations are the same as AA. Yet at the same time, it allows seasonal RH fluctuations of plus or minus $10 \%$ but minimum allowed $\mathrm{T}$ drop is $10 \mathrm{~K}$ instead of $5 \mathrm{~K}$. Apart from $\mathrm{A} 1$, the second sub-class, A2, allows short RH fluctuations of $10 \%$ while seasonal RH change is not allowable. Therefore, this class is expected to allow small risk of mechanical damage to highly vulnerable artifacts like paper-based collections.

Class B relatively allows higher seasonal and short changes in $\mathrm{T}$ and $\mathrm{RH}$. Short $\mathrm{RH}$ and $\mathrm{T}$ fluctuations may be within the range of $\pm 10 \%$ and $\pm 5 \mathrm{~K}$, respectively. On the other hand, seasonal changes are allowed to be $\pm 10 \%$ for $\mathrm{RH}$ and up to $5 \mathrm{~K}$ (but not above $30^{\circ} \mathrm{C}$ ) and down to as low as necessary to maintain RH control.

Classes $\mathrm{C}$ and $\mathrm{D}$ avoid risks that may occur due to excessively high or low levels of humidity. Both classes are generally considered as sufficient control classes for moderately valuable books while more valuable objects are required to be controlled with upper classes (Steeman et al., 2010).

\section{The case study: Necip Paş library Tire-Izmir, Turkey}

The library buildings were special type of buildings mostly constructed as the part of education complex in the Ottoman Empire. The first library constructed as the standalone building functioning to house the manuscripts in the Ottoman Empire is Köprülü
Library which was built by Köprülü Fazll Mustafa Paşa in the late seventeenth century. Following the late eighteenth century, many libraries such as Yusuf Ağa, Rodosi Ahmet Ağa, Raşid Efendi, Vahid Paşa, Derviş Mehmed Paşa, Zeynelzade, Yusuf Ziya Paşa, Tekelioğlu, Çaşnigir, Necip Paşa and Kavalah Mehmed Ali Paşa, were built in the cities other than İstanbul. These are the libraries that were built with local materials and construction techniques during the Ottoman Empire Era (Yıldırım, 2004).

Necip Paşa Library, which is located in Tire-İzmir, Turkey (Fig. 1), was built in 1827 by Mehmet Necip Paşa who was a statesman during the reign of Sultan Mahmut II to house his own collection accumulated during his official service in several places in the Ottoman Empire, and especially in Damascus and Baghdad (Yıldırım, 2004). Later, he established a foundation in order to financially support the expenditures of the library and preserve the books. The library today contains 1156 manuscripts, 1312 books printed in the era of Ottoman Empire and more than 9000 books in Latin letters, most of which was printed right after the foundation of the Republic of Turkey (Hatipoğlu, 2013; TR, 2016; Yıldırım, 2004). The library now provides the service to the researchers under the control and management of The Turkish Prime Ministry, Directorate General of Foundations.

The library, which lies on the north-south axis, originally has a porch (Revak/entrance) with an inclined roof and an almost square planned main hall, which is $8.8 \times 9.0 \mathrm{~m}$, covered with a dome. The porch area, namely entrance, was later covered with wooden-frame and single glazing windows and has been used as the office and reading hall by the library administrator and visitors since 1930 (Fig. 2a). The walls have a non-homogeneous composition composed of rubble stone and brick. There are seven windows on the walls, one of which is on the north and the others are distributed to the remaining directions by twos, and one entrance door opening to the south. However, the windows on the south are dormant because the bookshelves in the main hall are situated right in front of the windows. Besides, there are four fixed small windows on the rim of the dome, each facing to the four main directions (Fig. 2).

The main hall of the library has no HVAC system and is naturally ventilated by opening the windows and the door. Only the entrance zone is air-conditioned with a split type air conditioner. Therefore, the manuscripts are kept in free-floating microclimate (Şahin, Coşkun, Gülhan, Durmuş Arsan, \& Gökçen Akkurt, 2016). However, the building was intentionally erected above the platform, of which height is about $2 \mathrm{~m}$ from the ground level, in order to protect the books and manuscripts against humidity risk driven by the groundwater. This is the indication that historic buildings have considered the passive, architectural solutions to provide desired indoor microclimatic conditions.

The main hall consists of two spaces: the collections with Latin alphabet are exhibited in the main hall while the manuscripts are separately preserved in a cage-like-structure, namely manuscript zone, located on the center of the main hall (Bayraktar, 2003). The latter which was built later in 1908 has an octagonal shape of made 


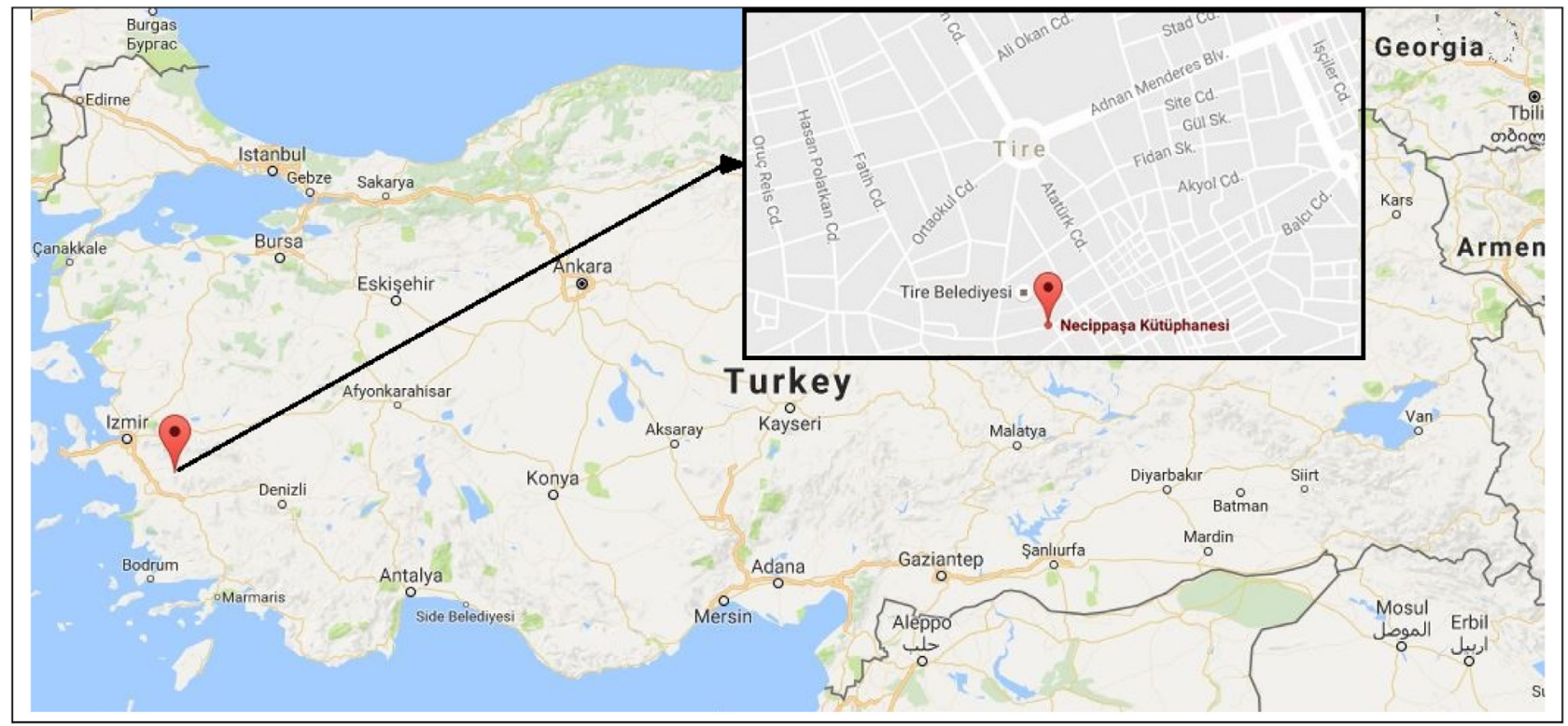

Fig. 1. Location of Necip Paşa Library.

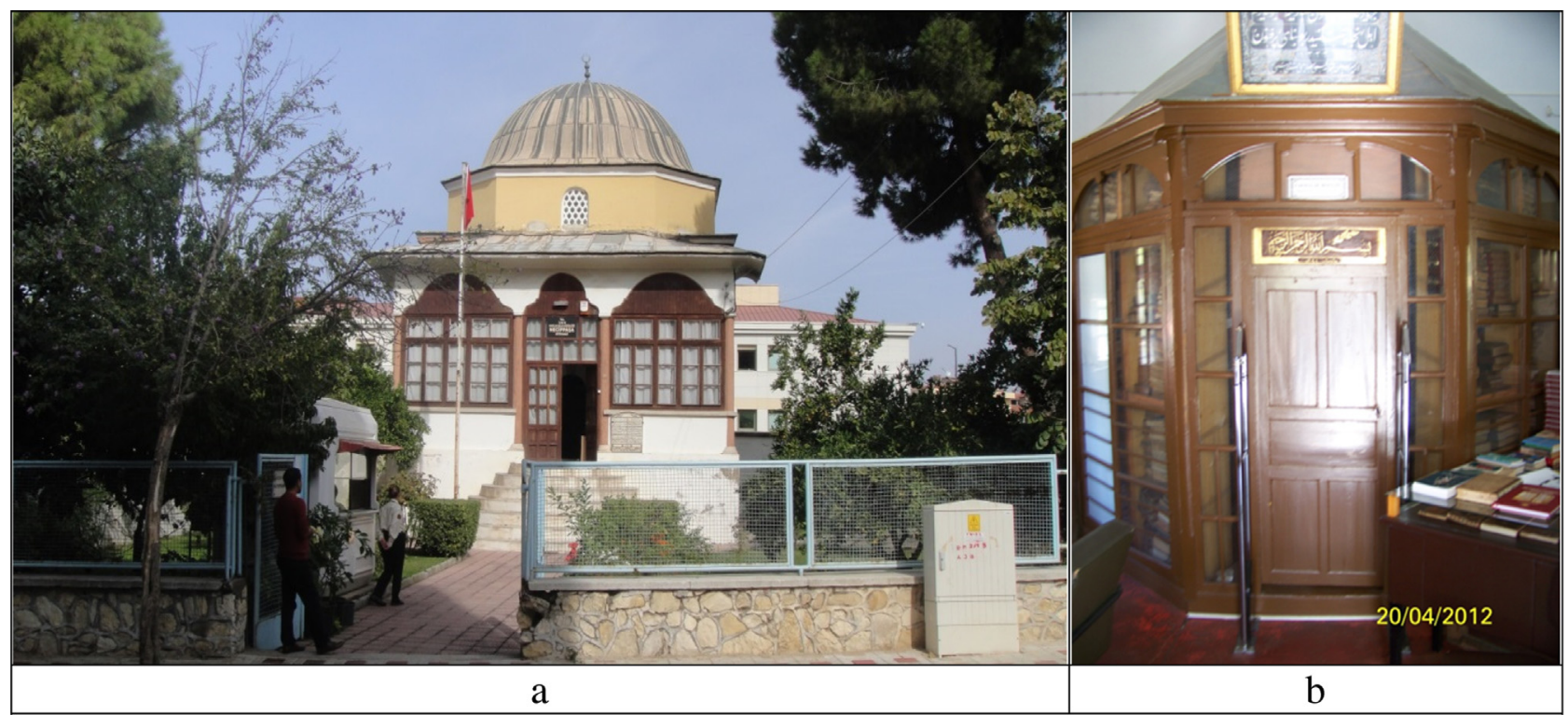

Fig. 2. a) South façade of Necip Paşa Library and b) the manuscript zone (UMART, 2016).

out of wooden and glass shutters and fences on each side (Fig. 2b) (UMART, 2016). The shutters are openable and used for ventilation purpose. The fences protect the manuscripts from insects and mice. Moreover, there is a hole on top of the manuscript zone, supposedly, to provide air circulation. The manuscripts are only allowed to be reached in this space for safety reasons. More detailed view of the manuscript zone indicated via A-A cross-section of the library can be seen in Supplementary material (Fig. S2).

Necip Paşa Library holds historically valuable and prominent manuscripts some of which are el-Ișarat and Kitabü'ş-Sifa of Ibni Sina, replicated in 1160, Şerhu'l-Menar fi Usul-i written by Ibni Melek in 1418 and Ma'rifetname by Ibrahim Hakkı in 1772 (Supplementary material, Fig. S1). More detailed search can be done online from the webpage of the Library (Tire Necip, 2015). For the time this study was being conducted, condition of the manuscripts was observed and their current situation was asked to the administrator of the library. According to the obtained information, it can be stated that the majority of manuscripts are in good condition except a small number of which have discoloration and embrittlement in pages due to the misuse (Yildırım, 2015). Very few number of occasions in terms of biological degradation has been supposedly observed (Üstün, 1994). Furthermore, moisture was observed, by the authors, on some parts of the floor of the mail hall during winter season, which might be highly favorable for mould germination in the library.

\section{Method}

The manuscripts will be investigated under four main risk assessments such as general indoor climate, mechanical, chemical and biological degradation. 
Table 2

Interpretation of the eLM values.

\begin{tabular}{llllll}
\hline & Ideal & Good & Some risk & Potential risk & High risk \\
\hline$e L M$ & $>2.2$ & $1.7-2.2$ & $1-1.7$ & $0.75-1$ & $<0.75$ \\
\hline
\end{tabular}

\subsection{General climate risk assessment}

The classes AA, A and B will be taken into account to assess the degradation risk of manuscripts in this study. The indoor climate will be assessed due to if thermo-hygrometric parameters are within the bandwidth of each climate class (Section 4.5.1).

\subsection{Mechanical degradation}

Mechanical degradation is subjected to the short fluctuations (hourly, daily, weekly) in RH. Hence, fluctuations in any desired time span can be obtained by the difference between minimum and maximum values over length of specified time. The results of each climate control class will be assessed according to the values indicated in the short fluctuation column of Table 1.

\subsection{Chemical degradation}

Chemical degradation risk will be assessed with the help of LM (Eq. (1)) which can be interpreted by means of two limit values, 0.75 and 1 . LM values below 0.75 and over 1 refer to high and low risk, respectively while those are in between correspond to medium risk of degradation (Martens, 2012). In order to make a general yearly statement over the LM results, an equivalent Lifetime Multiplier ( $e L M)$ that represents the average of reciprocal values of LM can be used instead of arithmetic average (Eq. (2)). Equivalent Lifetime Multiplier, which is a unique value enabling to evaluate the annual impact, vitalizes the impact of the points having worse conditions. Table 2 gives how eLM values should be interpreted (Silva \& Henriques, 2015).

$$
\begin{aligned}
& L M_{x}=\left(\frac{50 \%}{R H_{x}}\right)^{1.3} \times e^{\frac{E_{a}}{R} \cdot\left(\frac{1}{T_{x}+273.15}-\frac{1}{293.15}\right)} \\
& e L M=\frac{1}{\frac{1}{n} \times \sum_{x=1}^{n}\left(\frac{50 \%}{R H_{x}}\right)^{1.3} \times e^{\frac{E_{a}}{R} \cdot\left(\frac{1}{T_{x}+273.15}-\frac{1}{293.15}\right)} .} .
\end{aligned}
$$

\subsection{Biological degradation}

In the assessment of biological degradation risk, the investigation will be carried out separately for the main hall and the manuscript zone since both spaces have different structural boundaries and substrates, hence isopleths. Yet, investigating the mould growth risk in the main hall can be interpreted as an extensive analysis since the manuscript zone is contained by the main hall. Similar to previous studies, the evaluation will be conducted via superimposing the indoor microclimatic conditions onto isopleths (limit curves) (Silva \& Henriques, 2015; Vereecken \& Roels, 2010; Rowan et al., 1999).

Eq. (3) defines the critical RH level for porous materials used in the building envelope while Eq. (4) is used for wooden materials. A study to determine the atmospheric aerofungi via Durham trap procedure in İzmir indicates that Cladosporium, Altermaria, Penicillium, Phoma and Aspergillus are the prominent species (Çeter \& Pınar, 2009). Eq. (3) gives the critical RH for the mould specie of Aspergillus versicolor which is expected to have higher germination risk and hence, lowest isopleths. Furthermore, it shows a good agreement with a couple of germination isopleths for natural porous materials. Eq. (4) can be used if the material is exposed to the conditions for a long enough time (Vereecken \& Roels, 2010). Therefore, it can be said that both equations are sufficient to make mould growth analysis for this study.

$$
\begin{aligned}
& R H_{\text {crit }}=0.033 T^{2}-1.5 T+96 \\
& \text { when } T<30^{\circ} \\
& R H_{\text {crit }, w}= \begin{cases}-0.00267 T^{3}+0.160 T^{2}-3.13 T+100 & \text { when } T<20^{\circ} \\
80 & \text { when } T \geq 20^{\circ}\end{cases}
\end{aligned}
$$

The simplest way to determine the mould germination is to count the points that exceed the limit curve, which refers to the synthetic parameter of mould risk factor (MRF) (Silva \& Henriques, 2015). In order to scale the risk level of mould growth, two limit values, 0.5 and 1.0 , are introduced since the MRF value over 1.0 is assumed to be highly risky (Silva \& Henriques, 2015). Therefore, the MRF values below 0.5 has low risk while that of in between has medium risk of mould germination.

\subsection{The measurements and calculation of statistical parameters}

In order to evaluate indoor climate from the perspective of preventive conservation approach, continuous monitoring campaign of the thermo-hygrometric parameters and the airtightness measurements were performed. Besides, a number of statistical parameters that are assistive to make reliable risk assessment according to the ASHRAE Chapter 21 were calculated.

\subsubsection{Measurement of thermo-hygrometric parameters and airtightness}

Measurements of indoor and outdoor microclimatic parameters were carried out for one whole year between the dates 01/09/2014 and 31/08/2015 with 10 min intervals. Yet the natural indoor trend of the building could be recorded for approximately 10 months due to the beginning of restoration work by 01/07/2015. Five data loggers, four inside and one outside, were located for the measurements of thermo-hygrometric parameters. Two data loggers were mounted on the shelves, one west and one east, in the main hall at the height of $1.8 \mathrm{~m}$. A data logger was placed in the manuscript zone while the other one was in the entrance of the building. The last device was carefully placed outside at the northeast corner of courtyard, in which it would not be exposed to direct sunlight and rain. The accuracies of $\mathrm{RH}$ and $\mathrm{T}$ sensors are $\pm 2.5 \%$ from $10 \%$ to $90 \%$ and $0.35^{\circ} \mathrm{C}$ from $0^{\circ}$ to $50^{\circ} \mathrm{C}$, respectively. Specifications of the data loggers respect to the uncertainties denoted in the standards EN15758 for T (EN, 2010b) and EN 16242 for RH (EN, 2012) The locations of the data loggers can be seen in Fig. 3 as red points indicated with alphanumeric names.

In case where $\mathrm{T}$ and $\mathrm{RH}$ are of interest in a monitored space, the indoor absolute humidity $(\mathrm{AH})$ is compared to the outdoor $\mathrm{AH}$. The indoor climate can be modelled as a consequence of outdoor. The calculation of $\mathrm{AH}\left(\mathrm{kg}_{\text {air }} / \mathrm{m}_{\text {air }}{ }^{3}\right)$ values, based on $\mathrm{T}\left({ }^{\circ} \mathrm{C}\right)$ and $\mathrm{RH}(\%)$, is given in Eq. (5) (Camuffo, 1998).

$$
A H=R H \cdot \frac{0.0132295}{273 \cdot 16+T} \cdot \exp \left(\frac{17 \cdot 2694 . T}{238.3+T}\right) \text { when } \mathrm{T}>0^{\circ} \mathrm{C}
$$

There are multiple ways of determining the airtightness value of a space, such as fan pressurization, pressure pulse and tracer gas method (Mattsson, Lindström, Linden, \& Sandberg, 2011). In this study, the airtightness value of Necip Paşa Library was measured with a blower door by conducting depressurizing experiment following the test instructions based on ISO 9972:2015 (Minneapolis Blower Door ${ }^{\mathrm{TM}}$, 2015; ISO, 9972, 2015). The blower door was mounted on the entrance door, and the remaining exterior openings were closed (Fig. 3). Having ensured that the test instructions were fully satisfied, measurements were run under 50 Pa pressure difference until a reasonably stable value (ACH50) was obtained. $\mathrm{ACH} 50$ indicates how many times per hour the entire volume of air 


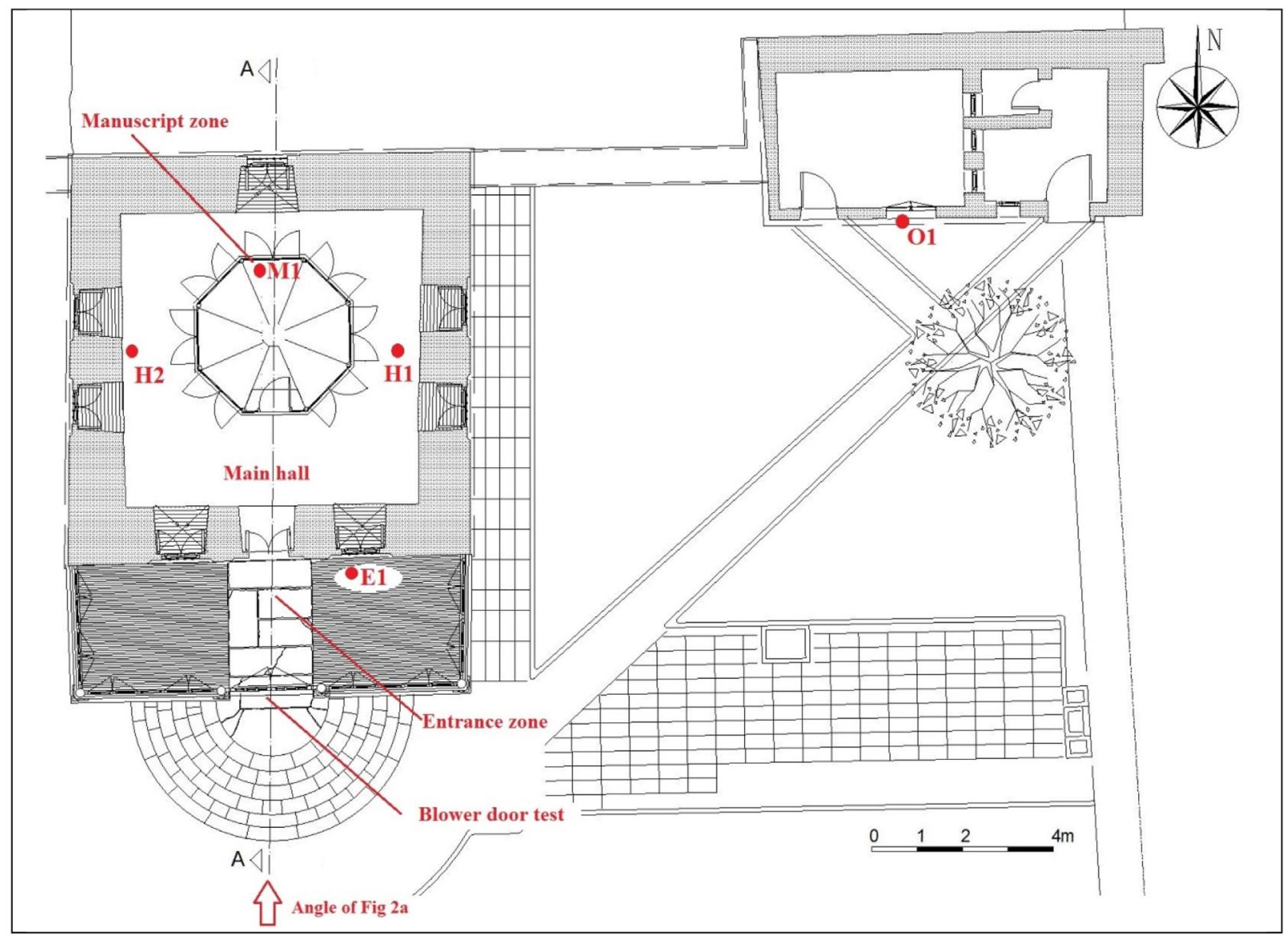

Fig. 3. Plan of the library and the location of data-loggers (UMART, 2016).

in the library is replaced when the space is exposed to 50 Pa pressure. In order to talk in more general terms, it is better to use average natural infiltration rate $(\mathrm{ACH})$, which can be calculated with Eq. (6)

Average natural infiltration rate $=\frac{A C H 50}{N}$

where $N$ is correlation factor associated with climate, height of the building, wind shielding and leakiness factors (Chen, Levine, Li, Yowargana, \& Xie, 2012; Minneapolis Blower Door ${ }^{\mathrm{TM}}$, 2015). However, such factors require detailed formulization and there is no clear guidance in Turkey to calculate $N$. Under these circumstances, it is suggested to divide ACH50 value by 20 , which gives a reasonably good estimate of average infiltration rate (Johnston \& Stafford, 2016; Meier, 1994).

\subsubsection{The statistical parameters for risk assessment}

In order to make reliable risk assessment, some statistical properties indicated in ASHRAE Chapter 21 need to be determined. For this purpose, mean value, seasonal running average (SRA), seasonal rise and drop and short-term fluctuations (only daily in this case) will be determined using Eqs. (7)-(10), respectively (Martens, 2012). In addition, the bandwidth, which is a useful indicator to better illustrate how satisfied the indoor climate due to the allowable limits, is individually determined for each climate class. Each parameter is obtained for both $\mathrm{T}$ and $\mathrm{RH}$.

$\bar{X}=\frac{1}{n} \sum_{i=1}^{n} X_{i}$
$X_{\text {running, } i}=\frac{1}{n} \sum_{a=i-0.5 n}^{i+0.5 n} X_{a}$

$X_{\text {rise }}=\max \left(X_{\text {running }}\right)-\bar{X}$

$X_{\text {drop }}=\bar{X}-\min \left(X_{\text {running }}\right)$

For convenience, it is better to calculate the statistical properties as following sequence. First, mean value, which refers to historic annual average indicated in the "set-point or annual average column" of Table 1, is obtained. At this point, it would be better to highlight that the indoor climate may be controlled due to set point or historic annual average. Since the primary aim of this study is to evaluate whether or not the hygrothermal behavior (without any HVAC system) of Necip Paşa Library satisfies the ASHRAE requirements, historic annual average will be taken into account for the risk assessment. After, historic annual average is lifted and lowered with the seasonal adjustments indicated in the seasonal adjustments in system set point column of Table 1 to determine maximum and minimum value for the allowed seasonal shift. Then, seasonal running average (SRA) is determined centering a measurement point that looks back and forward one and a half month (Eq. (7)). Therefore, evaluation of whole year should be carried out including 1.5 months before and after the period, which is done by mirroring the original data (Martens, 2012). If the SRA is exceeded the maximum and minimum allowed value, it is replaced by the limiting values. Finally, bandwidths are calculated simply lifting ando lowering the SRA by the allowed short fluctuations (Martens, 

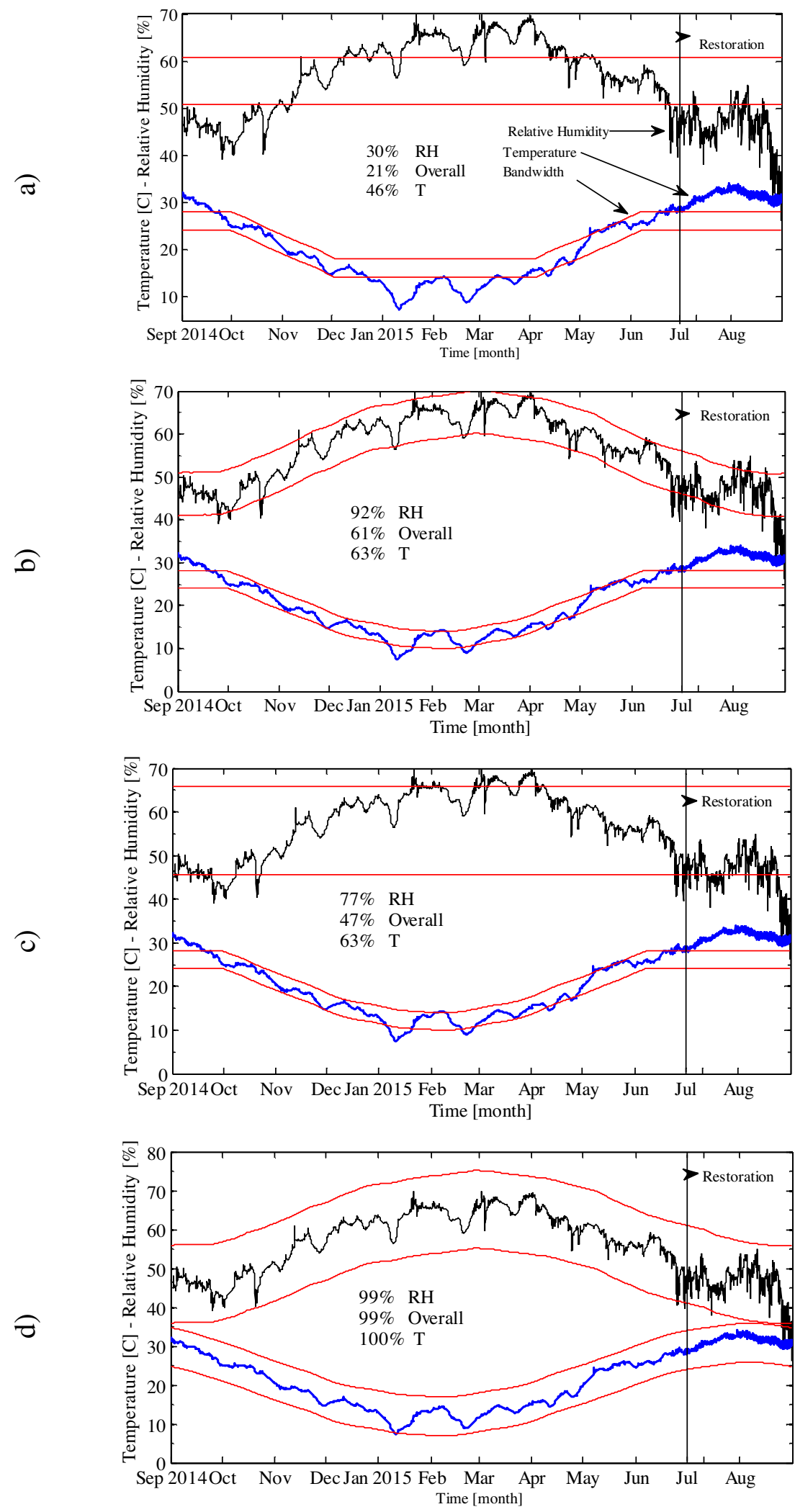

Fig. 4. Climate risk assesment according to ASHRAE climate classes a) AA, b) A1, c) A2, d) B.

2012). Seasonal rise and drop are calculated based on subtracting maximum value of SRA from mean value and mean value from minimum value of SRA, respectively.

\section{Results}

4.1. General climate risk assessment

General climate risk assessment results for paper-based collections based on ASHRAE Chapter 21 are given in Fig. 4. The date 
Table 3

Climate classes within bandwidths on monthly basis (\%).

\begin{tabular}{|c|c|c|c|c|c|c|c|c|c|c|c|c|}
\hline & \multicolumn{3}{|l|}{$\mathrm{AA}$} & \multicolumn{3}{|l|}{ A1 } & \multirow{2}{*}{$\begin{array}{l}\mathrm{A} 2 \\
\mathrm{~T}\end{array}$} & \multirow[b]{2}{*}{ RH } & \multirow[b]{2}{*}{ Overall } & \multirow{2}{*}{$\begin{array}{l}\mathrm{B} \\
\mathrm{T}\end{array}$} & \multirow[b]{2}{*}{$\mathrm{RH}$} & \multirow[b]{2}{*}{ Overall } \\
\hline & $\mathrm{T}$ & $\mathrm{RH}$ & Overall & $\mathrm{T}$ & $\mathrm{RH}$ & Overall & & & & & & \\
\hline September & 35 & 0 & 0 & 35 & 98 & 33 & 35 & 57 & 3 & 100 & 100 & 100 \\
\hline October & 100 & 9 & 9 & 100 & 91 & 91 & 100 & 67 & 67 & 100 & 100 & 100 \\
\hline November & 98 & 86 & 84 & 98 & 100 & 98 & 98 & 100 & 98 & 100 & 100 & 100 \\
\hline Autumn & 78 & 31 & 31 & 78 & 96 & 74 & 78 & 75 & 56 & 100 & 100 & 100 \\
\hline December & 71 & 33 & 25 & 100 & 100 & 100 & 100 & 100 & 100 & 100 & 100 & 100 \\
\hline January & 0 & 17 & 0 & 50 & 92 & 49 & 50 & 85 & 35 & 94 & 100 & 100 \\
\hline February & 7 & 15 & 0 & 57 & 92 & 57 & 57 & 83 & 46 & 100 & 100 & 100 \\
\hline Winter & 28 & 22 & 9 & 69 & 95 & 69 & 69 & 90 & 61 & 98 & 100 & 98 \\
\hline March & 30 & 0 & 0 & 100 & 96 & 96 & 100 & 28 & 28 & 100 & 100 & 100 \\
\hline April & 71 & 26 & 14 & 71 & 95 & 67 & 71 & 83 & 54 & 100 & 100 & 100 \\
\hline May & 67 & 75 & 46 & 67 & 100 & 67 & 67 & 100 & 67 & 100 & 100 & 100 \\
\hline Spring & 56 & 34 & 20 & 79 & 97 & 77 & 79 & 70 & 49 & 100 & 100 & 100 \\
\hline June & 71 & 78 & 70 & 72 & 93 & 70 & 72 & 95 & 71 & 100 & 99 & 99 \\
\hline July & 0 & 2 & 0 & 0 & 87 & 0 & 0 & 66 & 0 & 100 & 100 & 100 \\
\hline August & 0 & 17 & 0 & 0 & 65 & 0 & 0 & 63 & 0 & 100 & 91 & 91 \\
\hline Summer & 24 & 32 & 23 & 24 & 82 & 23 & 24 & 74 & 24 & 100 & 97 & 97 \\
\hline Overall & 46 & 30 & 21 & 63 & 92 & 61 & 63 & 77 & 47 & 100 & 99 & 99 \\
\hline
\end{tabular}

when restoration work began is illustrated here with a vertical line fixed on the beginning of July. At this point, it is significant to draw attention for that the Library was evacuated and the books and manuscripts were moved to another place approximately a week before the restoration begins. Therefore, Fig. 4 should be interpreted accordingly.

Result of climate class of AA, which is the most favorable one for highly vulnerable and significant objects, indicates that $\mathrm{T}$ and $\mathrm{RH}$ were within the bandwidths of $46 \%$ and $30 \%$, respectively, which yields $21 \%$ in overall. Classes of A1 and A2 show closer results even though both have different RH limits. Class A1 fits the criteria with $61 \%$ of the time whose $\mathrm{T}$ is $63 \%$ and $\mathrm{RH} 92 \%$. Class A2 obtains a percentage of $63 \%$ and $77 \%$ for $\mathrm{T}$ and $\mathrm{RH}$, respectively, which yields $47 \%$ overall. Class B which has relatively wider bandwidths is within the allowable limits of $99 \%$. Hence, it can be roughly summarized that the initial results point out indoor climate needs interventions or strategies in order to satisfy relatively more sensitive climate classes other than class $B$.

The overall scores can be a good indicator for general overview; yet the assessment on monthly basis can help to make in-depth analysis of the indoor climate. Table 3 shows the percentages of $\mathrm{T}$ and RH, separately and overall, within the bandwidths of each climate classes on a monthly basis.

Table 3 reveals that AA is the class having lowest overall performance. In seasonal terms, winter is the worst season with $9 \%$ which is followed by spring, $20 \%$, summer, $23 \%$ and autumn, $31 \%$. According to the restrictions on seasonal fluctuations of $\mathrm{T}$ and $\mathrm{RH}$, September, January, February and March are the worst months while July and August are out of the bandwidth due to higher temperatures.

Results obtained with respect to class A1 gives relatively better results, which can be reasonably subjected to the permission on seasonal fluctuations. The best seasonal performance seems to be occurred during spring with $77 \%$ while the worst one is summer, $23 \%$. On the other hand, results based on class A2 suggest that indoor climate indicates similar performance with $\mathrm{A} 1$ on $\mathrm{T}$ level while $\mathrm{RH}$ percentages drop considerably due to the stable bandwidth. Thus, the worst months are September, July and August. Assessment due to class $B$ gives the best results both monthly and seasonally because of the wider bandwidths (Fig. 4). Besides, indoor climate trend out of bandwidth of each climate class, which indicates the dangerous zone of the year based on an interrupted horizontal line, is given in Supplementary material (Fig. S3).

\subsection{Mechanical degradation risk assessment}

Each climate class should be individually, yet at the same time, completely assessed in terms of degradation risks and the requirements. Therefore, short fluctuations are required to be considered with general climate risk assessment results. Fig. 5 illustrates the daily maximum $\mathrm{T}$ and $\mathrm{RH}$ differences and of cumulative frequencies in the manuscript zone and main hall, of which limits are given on the short fluctuations column of Table 1.

According to Fig. 5a, daily T fluctuations in both zones satisfy the ASHRAE requirements for all conservation classes until the beginning of restoration work. The manuscript zone shows acceptable trend until the restoration work. The wooden structure of the manuscript zone diminishes the $\mathrm{T}$ fluctuations when compared to the main hall. Fig. 5b illustrates cumulative frequency of daily maximum $\mathrm{T}$ differences in the manuscript zone, which indicates that $\mathrm{T}$ differences less than 2 and $1.5 \mathrm{~K}$ were about $98 \%$ and $92 \%$, respectively.

Fig. 5 c gives the comparison of daily maximum RH differences in the main hall and manuscript zone. Therefore, daily RH fluctuations in the manuscript zone show good agreement within the limits to some extent. Fig. 5d illustrates cumulative frequency of daily maximum $\mathrm{RH}$ differences in the manuscript zone, which reveals that $90 \%$ of the period in the manuscript zone was below the limit of $5 \% \mathrm{RH}$ change while majority of those above the limit occurred after the restoration work began.

\subsection{Chemical degradation risk assessment}

Chemical degradation risk of the manuscripts was assessed with the help of LM. The results for the manuscript zone are given in Fig. 6 at which the risk zones are divided and illustrated with horizontal lines according to their magnitude.

According to Fig. 6, the manuscripts are under medium risk of chemical degradation in months; November and April while in high risk between May and October. Accordingly, the indoor microclimate of manuscript zone poses high chemical degradation risk partly in spring and fall seasons and whole summer. Equivalent Lifetime Multiplier ( $e L M$ ) value was calculated to be 0.54 , which indicates the indoor climate of manuscript zone is highly risky.

\subsection{Biological degradation risk assessment}

Biological degradation risk was assessed with the help of isopleths. Assessment in both the main hall and the manuscript zone 
a)

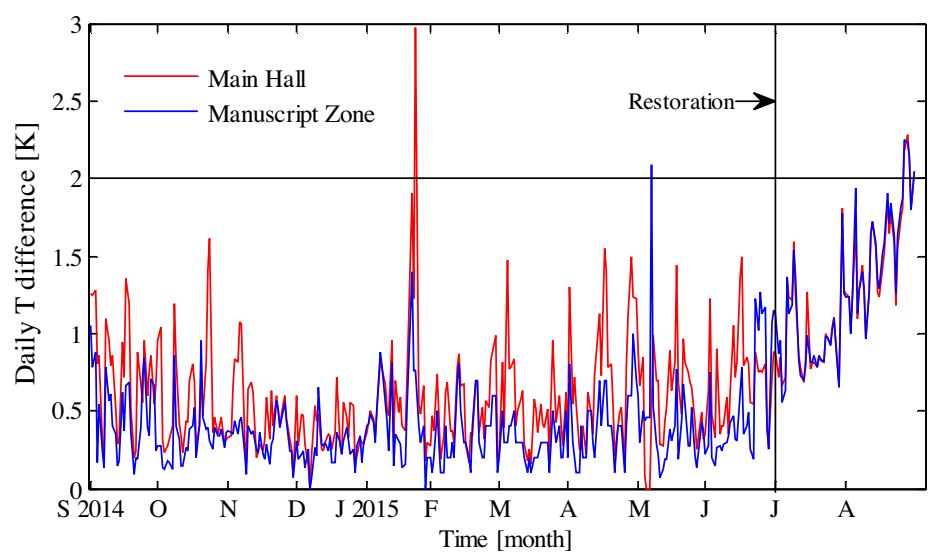

c)

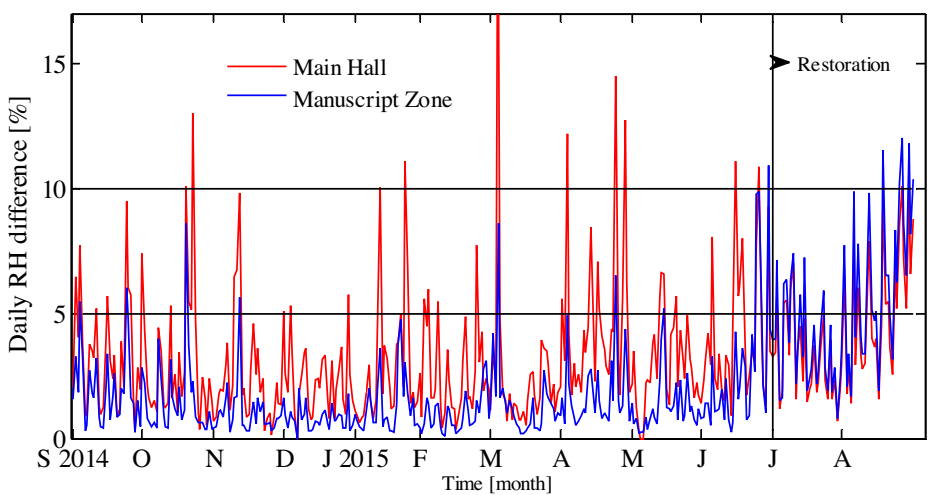

b)

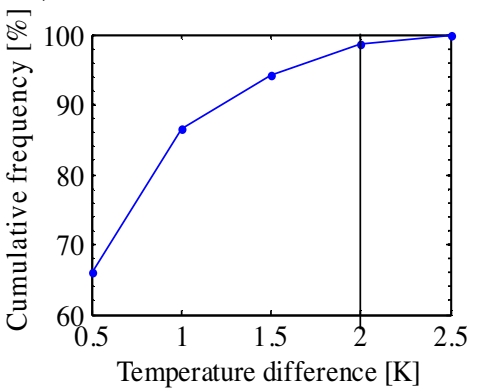

d)

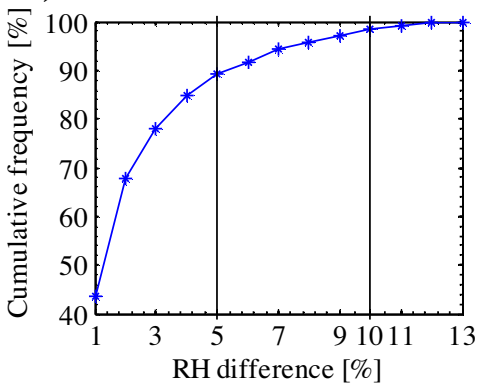

Fig. 5. Daily maximum $\mathrm{T}$ and $\mathrm{RH}$ differences and of cumulative frequencies.

were carried out based on superimposing the measured indoor climate data to limit curves. Fig. 7 shows the mould growth risk via isopleth for general wooden boundaries (manuscript zone) with light color while the dark color represents the main hall.

Fig. 7 shows that the indoor climate of main hall does not exceed the limit curve and stays in the safe region thus no risk of biological degradation exists. At this point, it is necessary to point out that the limit curve for main hall is valid up to $30^{\circ} \mathrm{C}$ while it was excessed throughout the measurement period. However, $\mathrm{RH}$ values were reasonably below the limit curve even though the temperature is over the equation's limit, which makes it tolerable and acceptable. The manuscript zone also indicates no risk of biological degradation showing the $\mathrm{RH}$ values no more than $70 \%$. Eventually,

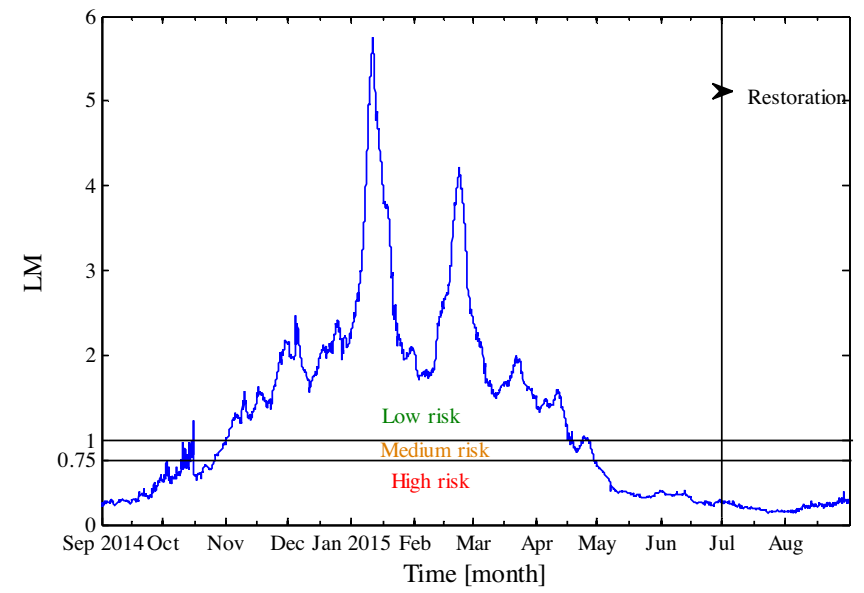

Fig. 6. LM for the manuscript zone on monthly basis. both zones can be concluded as safe or have low risk of biological degradation for the manuscripts.

\subsection{The measurements and calculation of statistical parameters}

\subsubsection{Measurement of thermo-hygrometric parameters and} airtightness

The measured outdoor data were first compared with the local statistics of Tire, İzmir, Typical Meteorological Year 2 (TMY2), which was obtained via Meteonorm v.6.1 software (Meteonorm v.6.1., 2016) (Supplementary material, Fig. S4). Mean value and standard deviation of measured temperatures were $19.3{ }^{\circ} \mathrm{C}$ and $8.5 \%$ while that of TMY2 were $18.7^{\circ} \mathrm{C}$ and $8.5 \%$, respectively. Besides, measured relative humidity and TMY2 have mean values of $65.6 \%$ and $56.5 \%$, respectively while standard deviation for measurements and TMY2 are $16.3 \%$ and $18.5 \%$, respectively. Mean values and standard deviations for both data were close meaning that there is no significant difference between them. Therefore, Fig. 8 illustrates the outdoor

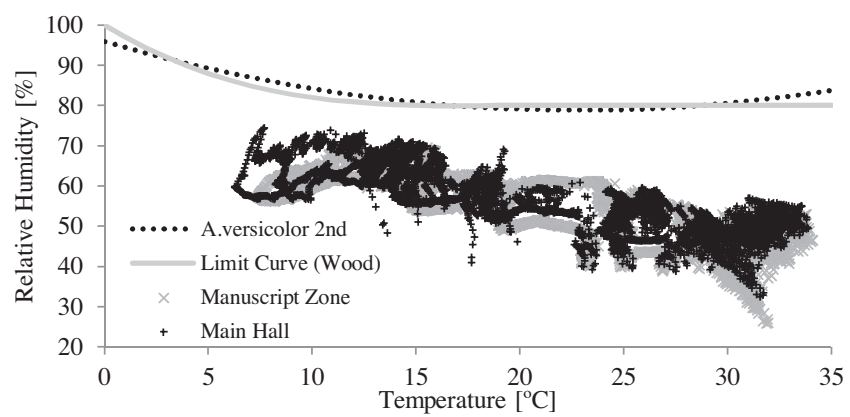

Fig. 7. Mould growth risk on the main hall and manuscript zone. 


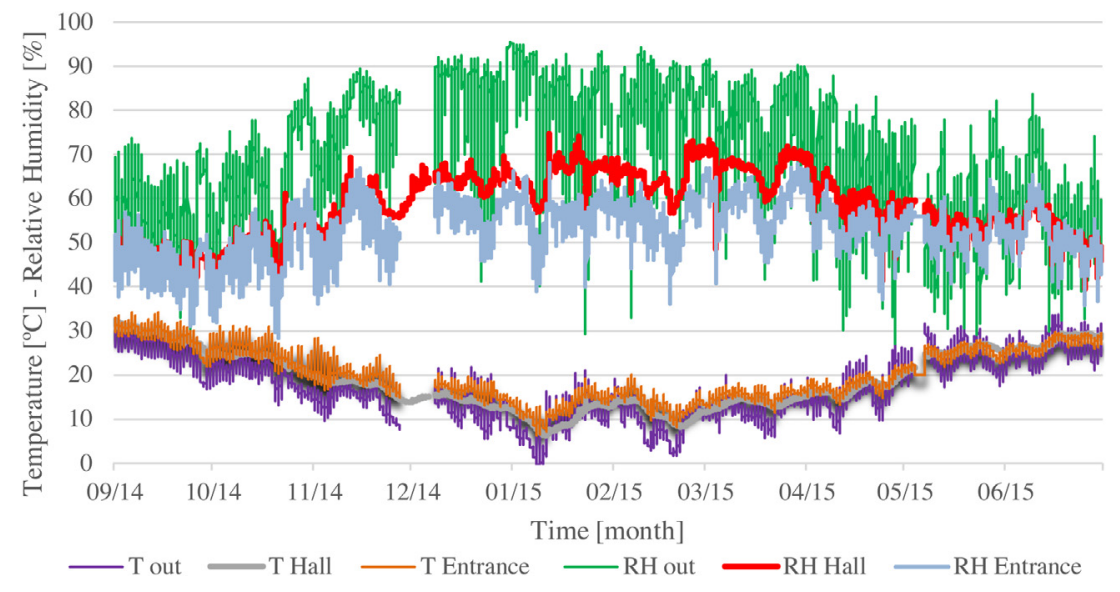

Fig. 8. Indoor and outdoor microclimate throughout the measurement period.

(O1) T and RH values as well as the entrance zone (E1) and the main hall trends that are the hourly average of measured values from $\mathrm{H} 1$ and $\mathrm{H} 2$ data loggers between 01/09/2014 and 30/07/2015.

Fig. 8 indicates that the entrance zone has higher $\mathrm{T}$ hence lower $\mathrm{RH}$ levels than the main hall which can be linked to the constructional differences and purpose of use. Since the entrance zone receives more solar gains due to comparatively large openings on its façade as well as active heat up in winter weekdays due to the librarians and library users, $\mathrm{T}$ is lifted which, in turn, affects the indoor $\mathrm{T}$ and $\mathrm{RH}$ of the main hall via air movement from the entrance zone.

Fig. 9 shows absolute humidity $(\mathrm{AH})$ trend of manuscript zone, the main hall and outdoor until the restoration work has begun. Maximum and minimum $\mathrm{AH}$ values for outdoor were observed in September $2014,0.018 \mathrm{~kg}_{\text {air }} / \mathrm{m}^{3}$ air and in January 2015 , $0.003 \mathrm{~kg}_{\text {air }} / \mathrm{m}^{3}$ air, respectively. On the other hand, maximum $\mathrm{AH}$ value, in the manuscript zone, was measured in September 2014, $0.016 \mathrm{~kg}$ air $/ \mathrm{m}^{3}$ air while that of minimum was in January 2015 , $0.005 \mathrm{~kg}_{\text {air }} / \mathrm{m}^{3}$ air .

Fig. 10a and b show the correlation of $\mathrm{AH}$ values of outdoor with the manuscript zone and the main hall, respectively. It can be stated that, the main hall shows better correlation with outdoor, $\mathrm{R}^{2}=0.80$, when compared to the manuscript zone, $\mathrm{R}^{2}=0.75$. Besides, the manuscript zone (0.0014) shows higher bias than that of main hall (0.0007).

Results of airtightness measurements show that the library has an air change rate of $0.52 \mathrm{ACH}$ which indicates roughly half of the air in the total volume (the main hall and entrance) changes over an hour.

Results of airtightness measurements show that the library has an air change rate of $0.52 \mathrm{ACH}$ which indicates roughly half of the air in the total volume (the main hall and entrance) changes over an hour.

\subsubsection{The statistical parameters for risk assessment}

Seasonal T and RH fluctuations in the manuscript zone were also calculated using Eqs. (8)-(9). Hence, seasonal T rise and drop were found $5 \mathrm{~K}$ and $9.9 \mathrm{~K}$, respectively. Seasonal RH fluctuations show $9.41 \%$ rise and $10 \%$ drop throughout the measurement period.

\section{Discussions}

To sum up, the hygrothermal behavior of Necip Paşa Library poses some risks especially in chemical degradation terms while biological and mechanical degradation risks are negligibly and avoidably lower. The manuscript zone appears to have considerable impact on stabilizing the indoor microclimate even though its door is kept open during working hours.

The climate class to be used for preventive conservation of manuscripts should be chosen carefully since any mistake on conservation policy may cause considerable damages, such as wrong HVAC system design and hence degradations on manuscripts. According to the results, it can be stated that the climate class A1 gives more appropriate outcomes to be considered as indoor climate control criteria for many reasons given below:

- The climate class allows seasonal fluctuations for both $\mathrm{T}$ and $\mathrm{RH}$. This allowance fits into the main objective of the study which focuses on and vitalizes the significance of free-floating hygrothermal behavior of the library. In parallel to these circumstances, general climate assessment results of A1 fall reasonably into the bandwidths with some minor exceptions.

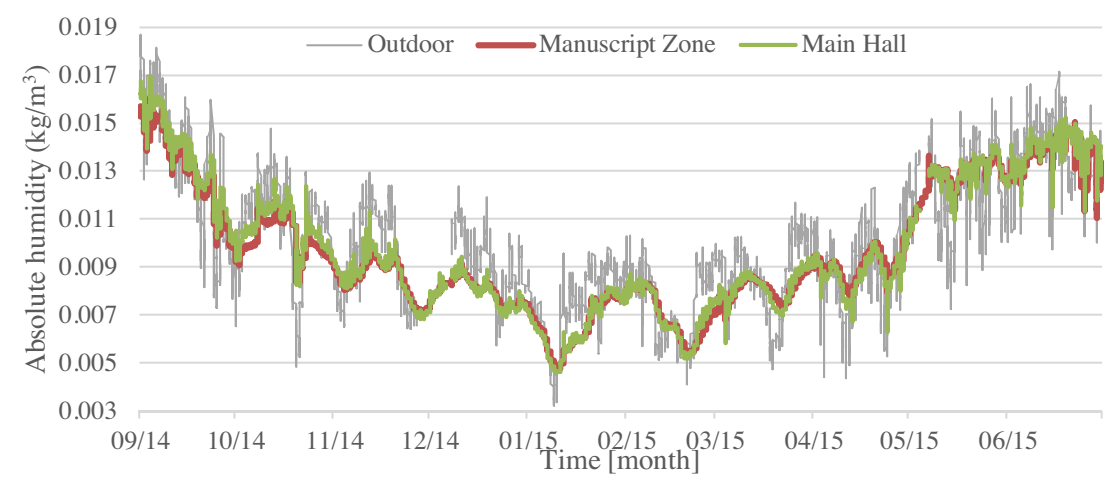

Fig. 9. Annual AH trend of the manuscript zone, main hall and outdoor. 

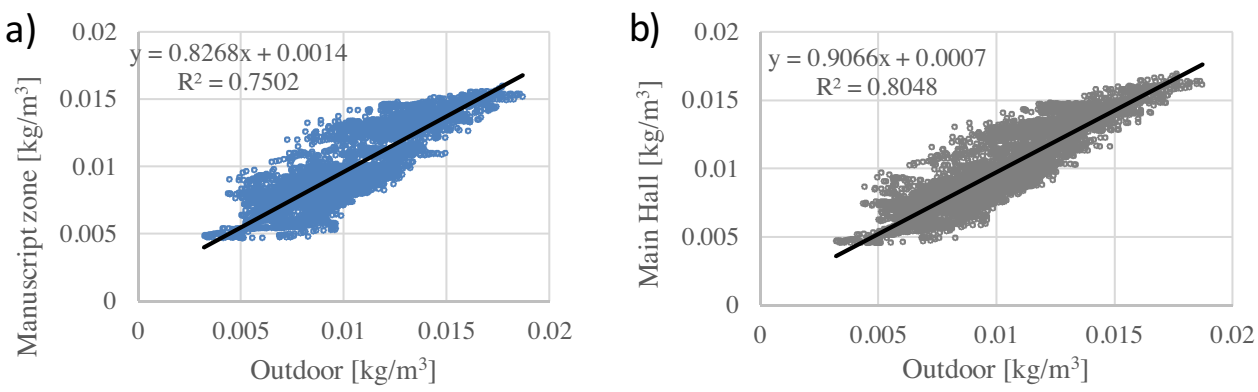

Fig. 10. The relation between outdoor $\mathrm{AH}$ and a) the manuscript zone b) the main hall.

- Short fluctuations indicated in the climate class A1 are sufficiently low to prevent mechanical degradation. It is, therefore, obvious that the indoor microclimate will diminish the risks of mechanical degradation as long as it is kept within the bandwidths.

- Chemical degradation is highly interrelated to the higher temperatures. Fig. 4b shows that temperatures in summer fall outside the bandwidth unless the measures that take into account of the ASHRAE Chapter 21 instructions are implemented.

- Biological degradation risk seems to be reasonably low since the bandwidth of A1 limits RH rise up to $70 \%$, which is considerably below the limit curve. Hence there is no need to take precautions to prevent mould growth if class A1 is taken into account.

Furthermore, the outcomes of this study needs to be compared with the similar studies which take into account of historic buildings that are conducted in similar climate, have high thermal inertia, no HVAC system, and of hygrothermal behavior is a prominent driven factor. The results of this study, to some extent, give parallel outcomes when compared to the similar studies in the literature since free-floating hygrothermal behavior of the library satisfies the biological and mechanical risk assessment criteria except chemical degradation (Andretta et al., 2015; Fabbri \& Pretelli, 2014). To authors' knowledge, there is no study considering the same approach upon the preventive conservation of manuscripts in historic libraries in Turkey.

\section{Conclusions}

In the present study, indoor climate of Necip Paşa Library was investigated in order to determine whether the free-floating hygrothermal behavior of the building is sufficient to prevent the manuscripts from degradations or not. Thermo-hygrometric parameters of the indoor environment were continuously monitored and benchmarked by the requirements indicated in ASHRAE Chapter 21. Moreover, some additional synthetic parameters, calculated depending on $\mathrm{T}$ and $\mathrm{RH}$, were utilized for better evaluation. As a consequence, following conclusions can be derived:

1 The first and foremost conclusion to be drawn is that the library has no continuous indoor climate monitoring system. Such systems should be installed as soon as possible so that precautions can be taken to tackle with the possible degradations in short, medium and long term. Short and medium term interventions can be applied with light mechanical solutions such as, adaptive ventilation and recirculation for particular time periods while that of long term should be implicated through passive solutions.

2 Chemical degradation is highly risky during partly spring and fall seasons and whole summer. This is mainly due to the higher temperatures and should, if possible, be solved with natural, if not, light mechanical solutions.

3 Indoor environment and hygrothermal behavior of the library should be well-analyzed before taking the decision of HVAC system installation in such buildings since the disturbing of past environmental history can cause unexpected consequences. Therefore, such HVAC measures should be first simulated in a building energy simulation tool.

4 The more airtight the building the less the mechanical degradation risk. Yet, the building should carefully be restored with an interdisciplinary decision mechanism in terms of airtightness since air-tightening the building envelope more than necessary might, at the same time, be problematic for minimum ventilation requirements for visitors.

5 ASHRAE climate class of A1 is the better option since it has tough limitations of $\mathrm{T}$ and $\mathrm{RH}$. Yet at the same time, A1 was chosen to be appropriate class since the manuscripts are highly valuable to be conserved.

6 The correlation obtained for the manuscript zone of AH shows higher bias and lower $\mathrm{R}^{2}$ when compared to that of the main hall. This can be explained with the high thermal mass of the building envelope and buffering effect of the books in the main hall. Thus, care must be given to the correlations when humidity control is of interest.

7 Manuscripts should only be allowed to be read inside the library to prevent the degradations that can be occurred due to the $T$ and RH fluctuations driven by different indoor environments.

8 Although ASHRAE Chapter 21 and other related guidelines were developed for the North America and of climate, the methods are widely used and recognized in other regions in the World. However, this study outcomes the need of a national standard. Since Turkey is very rich in cultural heritage (historic buildings and tangible cultural assets) it is suggested to develop national standards or adopt international standards for preventive conservation with the liaison of paper conservators.

\section{Acknowledgements}

The authors wish to acknowledge and give their appreciations to Ali İhsan Ylldırım, who is the administrator of library, for his valuable help and kind patience throughout the study. Besides, the authors would also like to thank The Prime Ministry Directorate General of Foundations, Republic of Turkey for the permission to take measurements in the library and their co-operation. Additionally, many thanks should be given to the UMART Architecture and Engineering Inc. for the use of its old photos and measured drawings in this study.

\section{Appendix A. Supplementary data}

Supplementary data associated with this article can be found, in the online version, at http://dx.doi.org/10.1016/j.scs.2016.11.002. 


\section{References}

ANSI/ASHRAE Standard 55-2013. (2013). Thermal environmental conditions for human occupancy. Atlanta, GA: American Society of Heating, Refrigerating and Air-Conditioning Engineers,

ASHRAE. (2007). Museums, libraries and archives. In S. Owen Mark (Ed.), ASHRAE applications handbook (SI). Atlanta, USA: American Society of Heating, Refrigerating and Air Conditioning Engineers.

Andretta, M., Coppola, F., \& Seccia, L. (2015). Investigation on the interaction between the outdoor environment and the indoor microclimate of a historical library. Journal of Cultural Heritage, http://dx.doi.org/10.1016/j.culher.2015.07. 002

Bülow, A. E. (2002). Preventive conservation for paper-based collections in historic buildings. In PhD thesis. Leicester: De Montfort University.

Baydar, N. (2001). Passive conservation of manuscripts in libraries. Türk Kütüphaneciliği Dergisi, 15(4), 365-377, in Turkish

Bayraktar, M. S. (2003). Tire'de necip Paşa Kütüphanesi. Güzel Sanatlar Enstitüsü Dergisi, 11, 1-16, in Turkish.

Brimblecombe, P., Blades, N., Camuffo, D., Sturaro, G., Valentino, A., Gysels, K., et al. (1999). The indoor environment of a modern museum building, the Sainsbury Centre for Visual Arts, Norwich, UK. Indoor Air, 9(3), 146-164.

Broström, T., Eriksson, P., Liu, L., Rohdin, P., Ståhl, F., \& Moshfegh, B. (2014). A method to assess the potential for and consequences of energy retrofits in Swedish historic buildings. The Historic Environment: Policy \& Practice, 5(2), $150-166$.

CEN European Committee for Standardisation, Indoor environmental parameters for assessment of energy performance of buildings, assessing indoor air quality, thermal environment, lighting and acoustics. Standard EN15251, 2007.

Camuffo, D. (1998). Microclimate for cultural heritage. Amsterdam: Elsevier Science.

Ceter, T., \& Pinar, N. M. (2009). Studies on atmospheric aerofungi in Turkey and using methods. Asthma Allergy Immunology, 7, 3-10, in Turkish.

Chen, S., Levine, M. D., Li, H., Yowargana, P., \& Xie, L. (2012). Measured air tightness performance of residential buildings in North China and its influence on district space heating use. Energy and Buildings, 51, 157-164.

Corgnati, S. P., \& Filippi, M. (2010). Assessment of thermo-hygrometric quality in museums: method and in-field application to the Duccio di Buoninsegna exhibition at Santa Maria della Scala (Siena, Italy). Journal of Cultural Heritage, $11,345-349$

Costanzo, S., Cusumano, A., Giaconia, C., \& Giaconia, G. (2006). Preservation of the artistic heritage within the seat of the Chancellorship of the University of Palermo A proposal on the methodology regarding an environmental investigation according to Italian Standards. Building and Environment, 41, $1846-1859$

D’agostino, V., d'Ambrosio Alfano, F. R., Palella, B. I., \& Riccio, G. (2015). The museum environment: A protocol for evaluation of microclimatic conditions. Energy and Buildings, 95, 124-129.

de Guichen, G. (1999). Preventive conservation: a mere fad or far-reaching change? Museum International, 51(1), 4-6.

Derluyn, H., Janssen, H., Diepens, J., Derome, D., \& Carmeliet, J. (2007). Hygroscopic behavior of paper and books. Journal of Building Physics, 31(9), 9-34. http://dx. doi.org/10.1177/1744259107079143

EN. (2010). Conservation of cultural property -specifications for temperature and relative humidity to limit climate-induced mechanical damage in organic hygroscopic materials. pp. EN15757. European Committee for Standardisation (CEN).

EN, Conservation of cultural property - procedures and instruments for measuring temperatures of the air and the surface of objects. European Committee for Standardisation (CEN) (2010) EN15758.

$\mathrm{EN}$, Conservation of cultural heritage - procedures and instruments for measuring humidity in the air and moisture exchanges between air and cultural property. European Committee for Standardisation (CEN) (2012) EN16242.

Fabbri, K., \& Pretelli, M. (2014). Heritage buildings and historic microclimate without HVAC technology: malatestiana library in cesena, Italy, UNESCO memory of the world. Energy and Buildings, 76, 15-31.

Hatipoğlu, O. (2013). Tire necip pasha library and some of its illuminated manuscripts. Mukaddime, 8, 109-126, in Turkish.

Huijbregts, Z., Kramer, R. P., Martens, M. H. J., van Schijndel, A. V. M., \& Schellen, H. L. (2010). A proposed method to assess the damage risk of future climate change to museum objects in historic buildings. Building and Environment, 55, $43-56$.

ISO 9972:2015. Thermal performance of buildings-Determination of air permeability of buildings-Fan pressurization method.

Johnston, D., \& Stafford, A. (2016). Estimating the background ventilation rates in new-build UK dwellings-Is n50/20 appropriate? Indoor and Built Environment, http://dx.doi.org/10.1177/1420326X15626234, 1420326X15626234

Karaca, F., Alagha, O., \& Gören, S. (2009). A literature survey: investigation and risk assessment of the effect of indoor air quality on the artefacts stored in museums and historic buildings and proposing a proper HVAC control systems. In Proceedings of 9th national HVACER engineering congress, in Turkish.

Krüger, E. L., \& Diniz, W. (2010). Relationship between indoor thermal comfort conditions and the Time Weighted Preservation Index (TWPI) in three Brazilian archives. Applied Energy, 88, 712-723.
Kuzucuoğlu, A. H., Kiraz, M. N., Ünsalan, O., \& Taşdemir, İ. (2015). A documentation proposal for manuscripts in libraries a case study: İstanbul university faculty of letters rare books library. Bilgi Dünyası, 16(1), 141-159, in Turkish.

Kuzucuoğlu, A. H. (2014). Risk management in libraries: Archives and museums. IIB International Refereed Academic Social Sciences Journal, 15(5), 277-294.

La Gennusa, M., Rizzo, G., Scaccianoce, G., \& Nicoletti, F. (2005). Control of indoor environments in heritage buildings: Experimental measurements in an old Italian museum and proposal of a methodology. Journal of Cultural Heritage, 6(2), 147-155.

Luciani, A., Wessberg, M., \& Broström, T. (2013). The influence of air exchange on the stability of the indoor climate in skokloster castle. e-Preservation Science, $10,77-82$.

Martens, M. H. J. (2012). Climate risk assessment in museums, degradation risks determined from temperature and relative humidity data. In PhD thesis. Eindhoven University of Technology.

Mattsson, M., Lindström, S., Linden, E., \& Sandberg, M. (2011). Methods to identify air leakages in the building envelope of churches. In Postprints from the conference energy efficiency in historic buildings (pp. 129-138).

Meier, A. (1994). Infiltration: Just ACH50 divided by 20? Home Energy, 11(January (1)), 25-37.

Meteonorm v.6.1. Available: http://www.meteonorm.com. (Accessed: 29.10.2016)

Michalski, S. (1993). Relative humidity: A discussion of correct/incorrect values. In J. Bridgland (Ed.), 10th triennial meeting (vol. 2) (pp. 624-629). Washington, DC, 22-27: ICOM-CC. August

Michalski, S. (2003). Double the life for each five-degree drop, more than double the life for each halving of relative humidity ICOM committee for conservation. 13th triennial meeting Rio de Janeiro preprints, vol 1, 66-72.

Minneapolis Blower Door ${ }^{\mathrm{TM}}$, Operation Manual for Model 3 and Model 4 Systems. Available: http://www.energyconservatory.com/sites/default/files/documents mod_3-4_dg700_-_new_flow_rings_-_cr_-_tpt_-_no_fr_switch_manual_ce_0.pdf. (Accessed: 25.07.2015)

PAS. (2012). PAS 198 specification for environmental conditions for cultural collections. London: British Standards Institution.

T. Padfield, P. K., Larsen, L. A., Jensen, M. Ryhl-Svendsen, The potential and limits for passive air conditioning of museums, stores and archives. In: Contribution to the Museum Microclimates Conference. National Museum of Denmark. Cophenagen, Denmark ISBN 978-87-7602-080-4, November 19-23, 2007.

Rowan, N. J., Johnstone, C. M., McLean, R. C., Anderson, J. G., \& Clarke, J. A. (1999). Prediction of toxigenic fungal growth in buildings by using a novel modelling system. Applied and Environmental Microbiology, 65(11), 4814-4821.

Şahin, C. D., Durmuş Arsan, Z., Tunçoku, S. S., Broström, T., \& Gökçen Akkurt, G. (2015). A transdisciplinary approach on the energy efficient retrofitting of a historic building in the Aegean Region of Turkey. Energy and Buildings, 96, 128-139.

Şahin, C. D., Coşkun, T., Gülhan, Ö., Durmuş Arsan, Z., \& Gökçen Akkurt, G. (2016). Humidity control to reduce the degradation risks of manuscripts in necip Pasa library, tire, İzmir - Turkey. CLIMA 2016 - proceedings of the 12th REHVA world congress (vol. 9)

Şahiner, A. (2006). Moulds that are biological threat to the historic structures. Sanat Tarihi Dergisi, XV/1(April), 167-176, in Turkish.

Sherman, M. H., \& Chan, W. R. (2004). Building airtightness: research and practice. Lawrence Berkeley National Laboratory. Report No LBNL-53356.

Silva, H. E., \& Henriques, F. M. A. (2014). Microclimatic analysis of historic buildings: A new methodology for temperate climates. Building and Environment, 82, 381-387.

Silva, H. E., \& Henriques, F. M. A. (2015). Preventive conservation of historic buildings in temperate climates: the importance of a risk-based analysis on the decision-making process. Energy and Buildings, 107, 26-36.

Steeman, M., De Paepe, M., \& Janssens, A. (2010). Impact of whole-building hygrothermal modelling on the assessment of indoor climate in library building. Building and Environment, 45, 1641-1652.

TR. (2016). Prime ministry directorate general of foundations. Tire Necip Paşa Library. Available: http://www.vgm.gov.tr/icerikdetay.aspx?Id=5 (Accessed: 25.07.2015)

Tire Necip Paşa Library Official Web Page, Available: http://www.vgm.gov.tr/ npkutuphanearama.aspx (Accessed: 26.08.2015).

UMART. (2016). Architecture and engineering corporation.. Available: http://www. umart.com.tr/en/default.aspx (accessed: 01.08.2016)

Üstün, A. (1994). Recommendations about the conservation and presentation of the manuscripts and its covers in Necip Pașa Library-Tire. Vakıf Haftası Dergisi, $11,173-185$, in Turkish.

UNI. Beni di intresse storico artístico. Condizioni ambientali di conservazione. Misurazione ed analisi. Italian Standard: 1999. UNI 10829.

Vereecken, E., \& Roels, S. (2010). Review of mould prediction models and their influence on mould risk evaluation. Building and Environment, 51, 296-310.

Yıldırım, A. İ. (2004). Tire necip Paşa library catalogue of illuminated manuscripts. Tire, in Turkish.

Yıldırım, A. İ. (2015). Personal communication. Administrator of Necip Paşa Library., 05.08.2015. 